\title{
Recovery of Platinum Group Metals from Spent Catalysts Using Electroless Nickel Plating and Magnetic Separation
}

\author{
Yu-ki Taninouchi*1 ${ }^{*}$ Tetsuo Watanabe ${ }^{* 2}$ and Toru H. Okabe \\ Institute of Industrial Science, The University of Tokyo, Tokyo 153-8505, Japan
}

This study demonstrates a new process for physically recovering platinum group metals (PGMs) directly from spent automobile catalysts. Automobile catalysts mostly consist of a honeycomb-structured ceramic substrate coated with a porous catalyst layer supporting fine particles of Pt, Pd, and Rh. In the proposed process, in order to magnetically separate and concentrate the PGMs, ferromagnetic Ni is deposited on the PGM particles (or the catalyst layer) using an electroless plating technique. Experiments were performed using samples that simulated an automobile catalyst. Using the electroless plating process, Ni could be coated on the porous catalyst layer without requiring complicated pretreatments such as sensitization and activation. Furthermore, the PGMs (Pt, Pd, and Rh) could be extracted and concentrated in the form of a magnetic powder through magnetic separation performed after Ni deposition and subsequent pulverization. Thus, the proposed physical concentration process is feasible and effective, and this process can be extended for making the recycling of automobile catalysts more efficient and environmentally friendly. [doi:10.2320/matertrans.M-M2017801]

(Received November 7, 2016; Accepted December 27, 2016; Published February 3, 2017)

Keywords: platinum group metals, automobile catalyst, physical concentration, recycling, electroless plating, magnetic separation

\section{Introduction}

Among the platinum group metals (PGMs), $\mathrm{Pt}, \mathrm{Pd}$, and $\mathrm{Rh}$ are the essential constituents of automobile catalysts. Over the past 20 years, the demand for PGMs in autocatalyst preparation has been increasing largely because of the increase in automobile production as well as stricter environmental regulations; in 2015, approximately $40 \%$ of the worldwide demand for Pt, $70 \%$ of that for Pd, and $80 \%$ of that for Rh were related to their use as automobile catalysts. ${ }^{1)}$ The total PGM concentration in automobile catalysts is approximately 500 $5000 \mathrm{ppm},{ }^{2,3)}$ which is nearly a hundred to a thousand times that in their natural ores. ${ }^{2,4-6)}$ Furthermore, mineral resources of PGMs are highly localized in South Africa and Russia, 1,2,4) and their mining and smelting generates large quantities of waste and consumes a huge amount of energy. Therefore, spent automobile catalysts are the most important secondary resource for PGMs, and their recycling is essential not only for ensuring a steady supply of PGMs but also for preserving the natural environment.

Automobile catalysts mostly consist of a honeycomb-structured ceramic substrate coated with a porous catalyst layer containing PGMs. The ceramic substrate is composed of cordierite $\left(2 \mathrm{MgO} \cdot 2 \mathrm{Al}_{2} \mathrm{O}_{3} \cdot 5 \mathrm{SiO}_{2}\right)$ or a similar chemically stable ceramic material. The catalyst layer consists of various oxides such as $\gamma$-alumina $\left(\mathrm{Al}_{2} \mathrm{O}_{3}\right)$, ceria $\left(\mathrm{CeO}_{2}\right)$, and zirconia $\left(\mathrm{ZrO}_{2}\right)$; it has a high specific surface area and supports fine particles of $\mathrm{Pt}, \mathrm{Pd}$, and $\mathrm{Rh}$.

Usually, the catalysts collected from used automobiles are mechanically pulverized in order to evaluate the PGM content, and then subjected to metallurgical processes for recovering the PGMs..$^{2-4,7)}$ The PGMs are purified and separated individually using various hydrometallurgical techniques such as solvent extraction, precipitation, and ion exchange. ${ }^{2,49}$ For this, the PGMs in the spent catalysts have to

\footnotetext{
${ }^{* 1}$ Corresponding author, E-mail: taninou@iis.u-tokyo.ac.jp

${ }^{* 2}$ Present address: Tanaka Kikinzoku Kogyo K.K., Ichikawa 272-0013, Japan
}

be dissolved in aqueous solutions, even though they show highly noble characteristics.

The PGMs can be dissolved directly from the spent catalysts by using acids containing strong oxidants such as aqua regia. ${ }^{10)}$ However, the disadvantages of the direct-dissolution process are its low PGM recovery rate and long processing time. Furthermore, the direct-dissolution process generates large amounts of toxic waste solutions and gases, owing to the low concentration and high chemical stability of the PGMs.

During commercial recycling processes, the PGMs in spent catalysts are often extracted and concentrated by pyrometallurgical techniques using a molten metal such as $\mathrm{Cu}$ or $\mathrm{Fe}$ as the collector ${ }^{11-13)}$ and then dissolved in an aqueous solution. In the pyrometallurgical process employed for concentrating PGMs using a collector metal, the ceramic components in the spent catalysts are removed as slag waste. The benefits of employing the pyrometallurgical process include its high PGM recovery rate and high throughput. However, the pyrometallurgical process requires large-scale equipment and uses a large amount of energy.

Physically concentrating the PGMs prior to metallurgical processes is advantageous for improving the efficiency of existing recycling processes. However, there have been few studies on the issue. The total PGM concentration in spent catalysts is less than 1 mass \%; the remaining mass consists of ceramics such as cordierite and $\mathrm{Al}_{2} \mathrm{O}_{3}$, which are converted into waste during the pyro- and/or hydrometallurgical processes. The PGM particles exist only in the porous catalyst layer coated on the ceramic substrate. Therefore, a simple, low-cost, and low-energy-consuming pretreatment process for physically separating the PGM particles or the PGM-containing catalyst layer directly from the spent catalyst would help significantly reduce the amount of energy consumed as well as the environmental burden of PGM recycling.

In the first half of the 1990s, Owada et al. proposed magnetic separation as a technique for physically separating the catalyst layer from pulverized automobile catalysts. ${ }^{14,15)}$ However, this technique is applicable only in the case of old 
catalysts, which contain a sufficient amount of Ni in the catalyst layer. Moreover, even in the case of Ni-containing automobile catalysts, the effective separation and concentration of PGMs have not been demonstrated experimentally. Owada et al. also proposed flotation after pulverization as a solution for physically concentrating PGMs. ${ }^{15-17)}$ However, the optimal flotation conditions for the efficient recovery of the catalyst layer have not yet been established. Selective grinding followed by size separation was reported to be helpful in concentrating the PGM-containing catalyst layer. ${ }^{18-20)}$ However, this technique is still in the development stage. The use of a heating/quenching process as a pretreatment to the selective-grinding process has also been explored. ${ }^{21,22)}$ Furthermore, techniques for the physical concentration of PGMs involving chemical pretreatments, such as alloying, sulfurization, and plating, have been proposed and studied recently. ${ }^{23-26)}$

The aim of this study was to experimentally demonstrate the feasibility of the novel process shown in Fig. 1 for the physical recovery and concentration of PGMs. The proposed technique is based on electroless $\mathrm{Ni}$ plating and magnetic separation $^{24-26)}$ and uses a concept suggested by Okabe and Mitsui. ${ }^{23)}$ In this process, calcination is performed to eliminate the undesired organic constituents such as carbon and sulfur present on the surfaces of the spent catalysts. Then, ferromagnetic $\mathrm{Ni}$ is deposited on the surfaces of the PGM particles and/or the catalyst layer using the electroless plating technique. Next, a heat treatment is performed, as needed, in order to enhance the adhesion of the deposited $\mathrm{Ni}$ and to promote the alloying of the PGMs with the deposited Ni. As mentioned above, automobile catalysts have complex honeycomb-like structures, and their catalyst layer is highly porous. Nevertheless, it is expected that the plating solution can be effectively supplied to the complex and porous surfaces of the catalysts. Electroless plating on a ceramic usually involves complicated pretreatments of its surface, such as sensitization and activation. However, in the case of automobile catalysts, it should be possible to perform the electroless deposition of $\mathrm{Ni}$ without such pretreatments because the PGM particles in the catalyst layer would act as catalysts for the electroless plating process. After the deposition of $\mathrm{Ni}$, the automobile catalyst is crushed and pulverized. Then, the Ni-attached portion (i.e., the PGM particles and/or the PGM-containing catalyst layer) is magnetically separated based on the ferromagnetic properties of Ni. This process allows the PGMs to be concentrated in the magnetic powder and the ceramic components (i.e., mainly the ceramic substrate) to be removed in the form of the nonmagnetic powder left behind. It should be noted that the deposited $\mathrm{Ni}$, which is used to concentrate the PGMs, can be employed as a collector metal for the subsequent pyrometallurgical recycling process. Furthermore, when the PGMs in the magnetic powder are alloyed with $\mathrm{Ni}$ in the appropriate amount, they can be extracted efficiently by direct dissolution in an acid.

\section{Materials and Methods}

\subsection{Preparation of catalyst samples 2.1.1 Plate-type sample}

Two types of catalyst samples, namely, plate-type and hon-
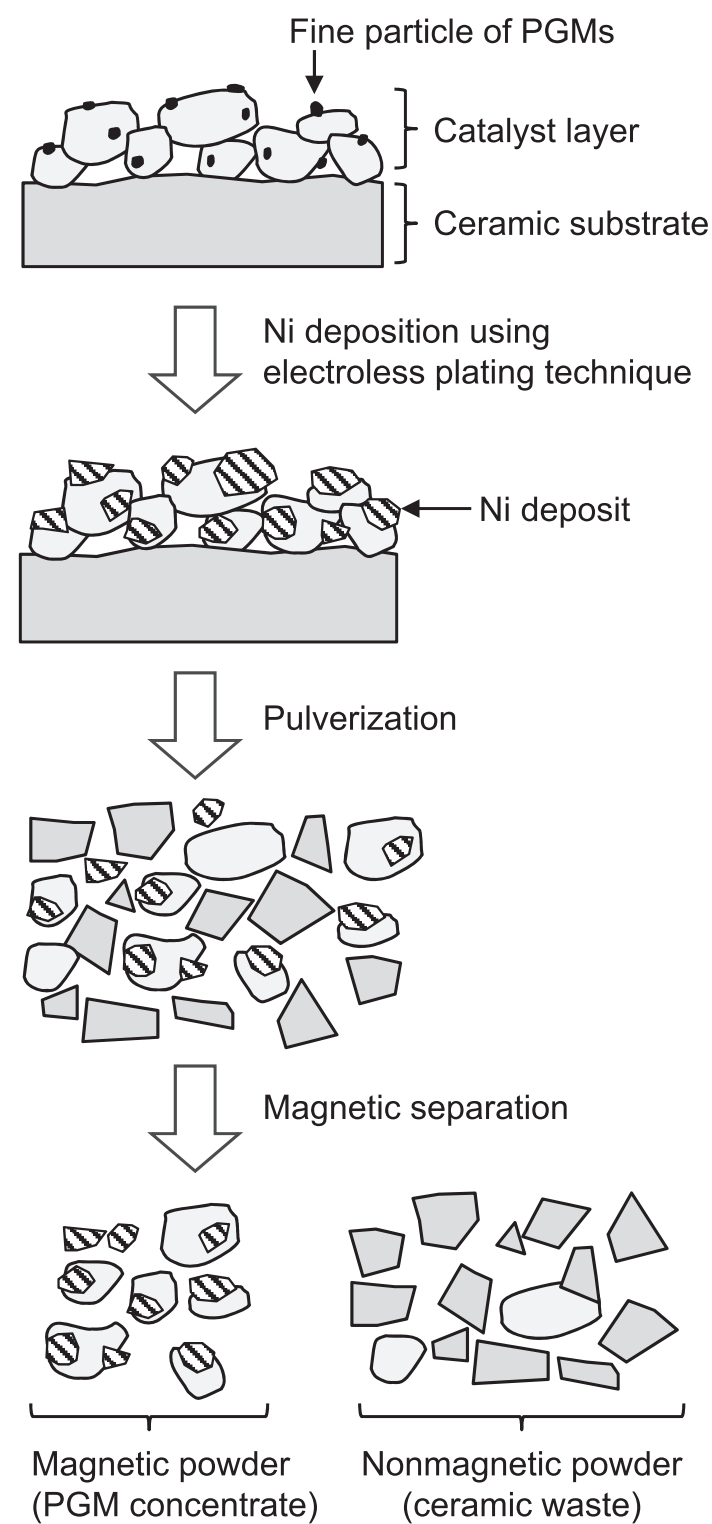

Fig. 1 Mechanism of the novel process for physically separating PGMs from spent catalysts. Ferromagnetic Ni is deposited on the PGM particles or the catalyst layer using the electroless plating technique. A heat treatment is performed as needed in order to improve the adhesion of the $\mathrm{Ni}$ deposit. Then, the Ni-deposited catalysts are pulverized and magnetically separated. This process is expected to concentrate PGMs in the magnetic powder and to remove the ceramic components in the form of the nonmagnetic powder.

eycomb-type samples, were prepared to simulate automobile catalysts. Figure 2 shows the procedure for preparing the plate-type catalyst samples. ${ }^{25,27,28)}$ As shown in Fig. 2(a), first, Pt-, Pd-, and Rh-loaded alumina powders were synthesized by baking an $\gamma-\mathrm{Al}_{2} \mathrm{O}_{3}$ powder $(>97.0 \%$, Strem Chemicals Inc.) mixed with aqueous solutions containing $\mathrm{Pt}\left(\mathrm{NH}_{3}\right)_{2}\left(\mathrm{NO}_{2}\right)_{2}, \mathrm{Pd}\left(\mathrm{NH}_{3}\right)_{2}\left(\mathrm{NO}_{2}\right)_{2}$, and $\mathrm{Rh}\left(\mathrm{NO}_{2}\right)_{2}$, respectively, at $673 \mathrm{~K}$. The PGM concentration in the Pt-, Pd-, and Rh-loaded $\mathrm{Al}_{2} \mathrm{O}_{3}$ powders was approximately 2 mass\%. As shown in Fig. 2(b), the Pt-, Pd-, and Rh-loaded $\mathrm{Al}_{2} \mathrm{O}_{3}$ powders were then mixed in a mass ratio of 1:1:1 to prepare the catalyst powder. A slurry-like solution was prepared by mixing the catalyst powder with boehmite powder $(\mathrm{AlOOH} \cdot$ $x \mathrm{H}_{2} \mathrm{O}$, Wako Pure Chemical Industries, Ltd.) and 5 vol\% 
(a)

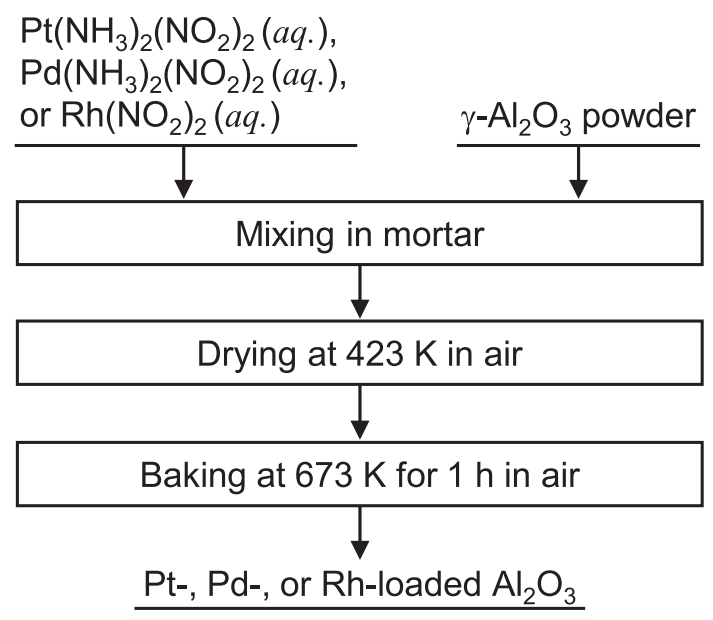

(b)

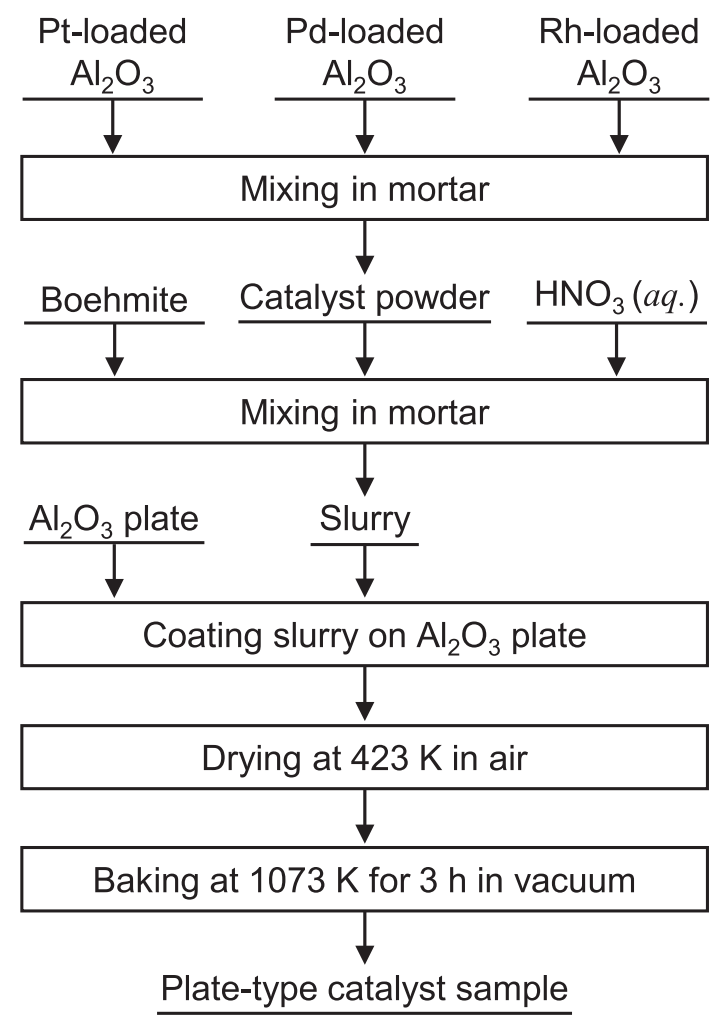

Fig. 2 Procedure for preparing (a) the $\gamma-\mathrm{Al}_{2} \mathrm{O}_{3}$ powder supporting $\mathrm{Pt}$, $\mathrm{Pd}$, or $\mathrm{Rh}$, and (b) the plate-type catalyst sample. The PGM concentration in Pt-, Pd-, or Rh-loaded $\mathrm{Al}_{2} \mathrm{O}_{3}$ was approximately 2 mass\%. A catalyst layer containing the PGMs was formed on the $\mathrm{Al}_{2} \mathrm{O}_{3}$ plate (approximately $25 \times$ $25 \times 0.5 \mathrm{~mm}$ in size). The mass of the plate-type samples was approximately $1.5 \mathrm{~g}$, and the concentration of each PGM was 0.04-0.06 mass\% (see Table 4).

$\mathrm{HNO}_{3}$ (aq.). The mass ratio of the catalyst powder and the boehmite powder in the slurry was 10:1. This slurry was coated on an $\mathrm{Al}_{2} \mathrm{O}_{3}$ plate $(99.5 \%$, Nikkato Co., Ltd.) with an area of approximately $25 \times 25 \mathrm{~mm}^{2}$ and a thickness of $0.5 \mathrm{~mm}$. After being dried at $423 \mathrm{~K}$, the slurry-coated plate was baked at $1073 \mathrm{~K}$ for $3 \mathrm{~h}$ in vacuum.

Figure 3(a) shows a photograph of the plate-type sample, while Fig. 3(b) shows a scanning electron microscopy (SEM) image of its cross-section. A porous catalyst layer, whose thickness was several hundred micrometers, was formed on the $\mathrm{Al}_{2} \mathrm{O}_{3}$ plate. The mass of the plate-type samples was approximately $1.5 \mathrm{~g}$, and the concentrations of the PGMs in the plate-type samples were 0.04-0.06 mass\% (see Table 4).

\subsubsection{Honeycomb-type sample}

The honeycomb-type samples were cut out from an unused automobile catalyst for gasoline vehicles and were subsequently heated at $1373 \mathrm{~K}$ for $5 \mathrm{~h}$ in air to simulate a spent catalyst. Figure 4 shows a photograph and an SEM image of a honeycomb-type catalyst sample. The thicknesses of the honeycomb-structured substrate and the porous catalyst layer were approximately $100 \mu \mathrm{m}$ and $30 \mu \mathrm{m}$, respectively. Further, the substrate consisted of Fe-doped cordierite, while the major components of the catalyst layer were $\mathrm{Al}_{2} \mathrm{O}_{3}, \mathrm{CeO}_{2}$, and $\mathrm{ZrO}_{2}$ (see Fig. 9 and Table 3). The mass of the honeycombtype samples was approximately $4.5 \mathrm{~g}$, and the concentrations of $\mathrm{Pt}, \mathrm{Pd}$, and $\mathrm{Rh}$ were 0.04-0.06 mass\%, 0.50.7 mass $\%$, and $0.07-0.1$ mass $\%$, respectively (see Table 4).

\subsection{Experimental procedure}

Figure 5 shows the experimental procedure for demonstrating the proposed physical concentration technique, and Table 1 lists the experimental conditions used in this study.

Ni was deposited using a common electroless plating bath whose composition is shown in Table 2 . The reducing and complexing agents used were sodium hypophosphite and glycine, respectively. The $\mathrm{pH}$ of the plating bath was $7.7 \pm 0.4$ at room temperature $(\sim 298 \mathrm{~K})$. Preliminary experiments indicated that the $\mathrm{Ni}$ deposit formed using the plating bath at $353 \mathrm{~K}$ contained 4 mass $\%$ P. To begin with, the catalyst sample was immersed in $40 \mathrm{ml}$ of the plating solution at room temperature. The gas bubbles remaining in the sample were removed by holding it at a reduced pressure for several minutes. The plating bath containing the sample was then heated at $343 \mathrm{~K}$ for $16 \mathrm{~min}$ in the case of the plate-type samples and at $353 \mathrm{~K}$ for $15 \mathrm{~min}$ in the case of the honeycomb-type samples, in order to initiate the electroless deposition of $\mathrm{Ni}$. In some of the experiments, the catalyst samples were heated at 913,1073 , or $1173 \mathrm{~K}$ for $3 \mathrm{~h}$ in vacuum after the electroless plating process.

After the Ni deposition process, the catalyst samples were crushed and pulverized in an agate mortar. Next, the magnetic separation of the pulverized catalyst samples was performed using a palm-sized neodymium magnet (Nd-Fe-B alloy, round in shape, $\phi 30 \times 15 \mathrm{~mm}$ ) under dry conditions. Magnetic separation was also performed after dispersing the samples in ethanol.

\subsection{Analyses}

In order to analyze the microstructures and compositions of the Ni-deposited catalyst samples, SEM and energy-dispersive X-ray spectroscopy (SEM/EDS) were performed using JSM-6510LV (JEOL) and JSM-6330F (JEOL) systems.

The PGM concentrations in the magnetic and nonmagnetic powders were analyzed using inductively coupled plasmaatomic emission spectrometry (ICP-AES). The sample solutions for ICP-AES were prepared using the alkali fusion and tellurium precipitation techniques. ${ }^{29,30)}$ The powder sample in question was mixed with $\mathrm{Na}_{2} \mathrm{O}_{2}$ and then fused in an $\mathrm{Al}_{2} \mathrm{O}_{3}$ crucible at $1073 \mathrm{~K}$. The mixing ratio of the powder sample 

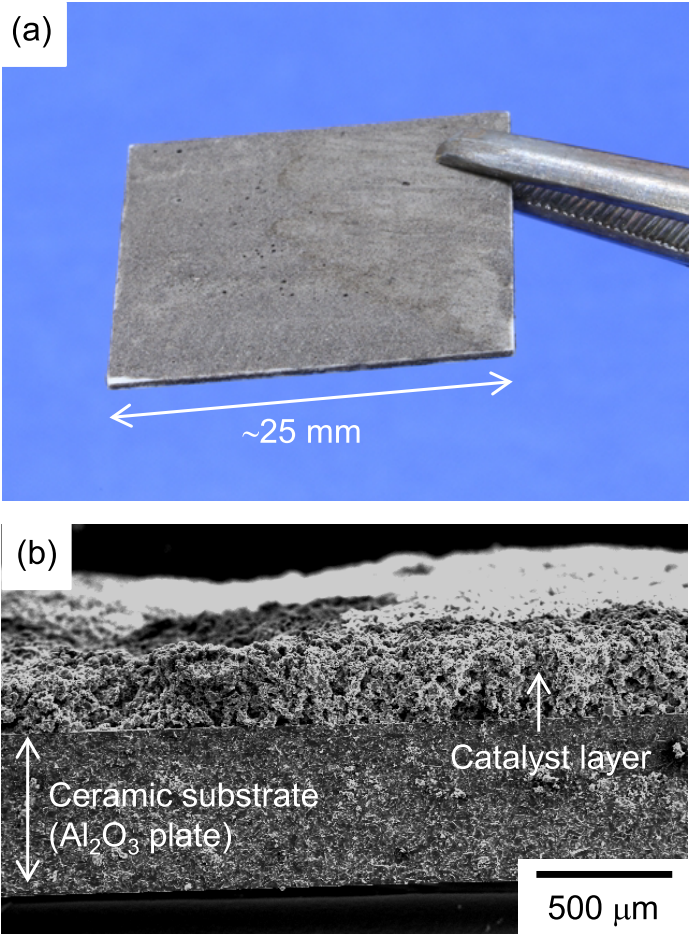

Fig. 3 (a) Photograph and (b) cross-sectional SEM image of a plate-type catalyst sample prepared in this study. The mass of the plate-type samples was approximately $1.5 \mathrm{~g}$, and the concentration of each PGM was 0.04 0.06 mass \% (see Table 4).
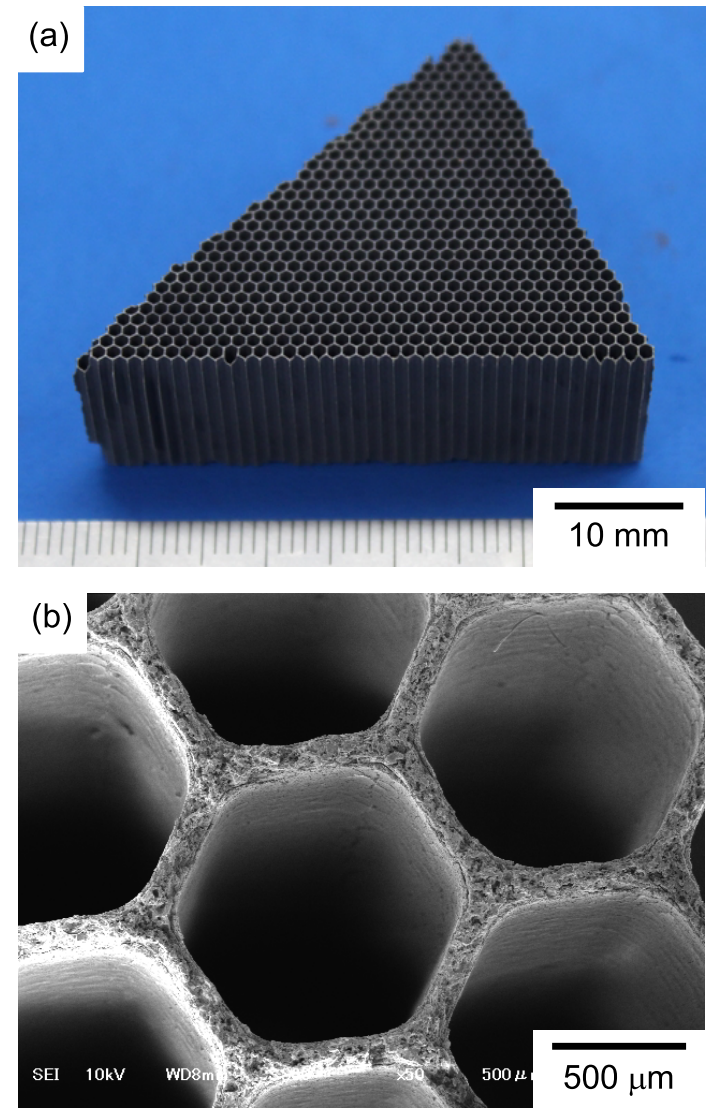

Fig. 4 (a) Photograph and (b) SEM image of a honeycomb-type catalyst sample. A test piece was cut out from an unused automobile catalyst and subsequently heated at $1373 \mathrm{~K}$ for $5 \mathrm{~h}$ in air. The mass of the honeycomb-type samples was approximately $4.5 \mathrm{~g}$, and the concentration of $\mathrm{Pt}$ $\mathrm{Pd}$, and $\mathrm{Rh}$ were $0.04-0.06$ mass\%, $0.5-0.7$ mass\%, and $0.07-$ 0.10 mass $\%$, respectively (see Table 4).
Plate-type or honeycomb-type catalyst sample

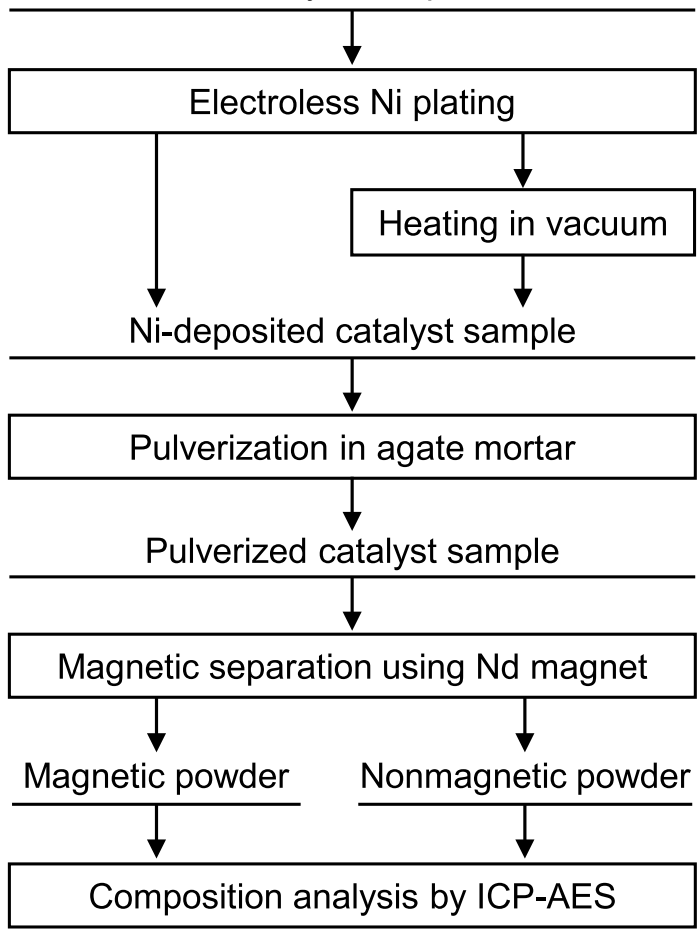

Fig. 5 Experimental procedure for demonstrating the physical concentration technique shown in Fig. 1.

and $\mathrm{Na}_{2} \mathrm{O}_{2}$ was $1: 10$ by weight. The product in the crucible was dissolved completely using a concentrated $\mathrm{HCl}$ solution. After the solution had evaporated completely, the resulting salt was dissolved again in $2 \mathrm{M} \mathrm{HCl}$. Next, the solution was filtered to remove the undissolved residue. This undissolved residue was observed in the case of the magnetic powder as well as the nonmagnetic powder derived from the honeycomb-type samples, and its major component was $\mathrm{SiO}_{2}$. The resulting filtrate, which was approximately $100 \mathrm{ml}$ in volume, was mixed with $10 \mathrm{ml}$ of a Te solution $\left(\mathrm{Te}: 10 \mathrm{mg} \cdot \mathrm{ml}^{-1}\right)$ and heated to $363 \mathrm{~K}$. Then, $30 \mathrm{ml}$ of a $20 \% \mathrm{SnCl}_{2}$ solution was added to it slowly, and the sample solution was kept at $363 \mathrm{~K}$ for $5 \mathrm{~h}$. The PGMs that coprecipitated with the Te were collected by filtration and dissolved in aqua regia. The resulting solution was evaporated completely to remove the $\mathrm{HNO}_{3}$. Finally, the resulting salt was dissolved in $2 \mathrm{M} \mathrm{HCl}$, and the sample solution was tested using ICP-AES. The PGM concentrations in the sample solution were analyzed using a SPS3520UV (SII NanoTechnology Inc.) system. For the ICPAES measurements, the analytical lines of $\mathrm{Pt}, \mathrm{Pd}$, and $\mathrm{Rh}$ were taken to be $203.712,340.458$, and $343.587 \mathrm{~nm}$, respectively.

In this study, the PGM concentrations in the catalyst samples before processing ( $C_{\text {cat }, i}$ (mass $\left.\%\right), i$ : Pt, Pd, or Rh) were evaluated based on the masses and PGM concentrations of the magnetic and nonmagnetic powders as follows:

$$
C_{\text {cat }, i}=\left(C_{\text {mag }, i} \times w_{\text {mag }}+C_{\text {nmag }, i} \times w_{\text {nmag }}\right) / w_{\text {cat }}
$$

where $C_{\mathrm{mag}, i}$ and $C_{\mathrm{nmag}, i}$ are the PGM concentrations in the magnetic and nonmagnetic powders as determined by ICPAES, respectively, and $w_{\text {cat }}, w_{\text {mag }}$, and $w_{\text {nmag }}$ are the masses of 
Table 1 Experimental conditions.

\begin{tabular}{|c|c|c|c|c|c|c|c|}
\hline \multirow[b]{3}{*}{ Exp. no. } & \multirow[b]{3}{*}{$\begin{array}{l}\text { Type of } \\
\text { catalyst sample }\end{array}$} & \multicolumn{4}{|c|}{ Ni deposition } & \multirow[b]{3}{*}{$\begin{array}{l}\text { Magnetic } \\
\text { separation }\end{array}$} & \multirow[b]{3}{*}{ Note } \\
\hline & & \multicolumn{2}{|c|}{ Electroless plating } & \multicolumn{2}{|c|}{ Heat treatment ${ }^{\mathrm{c}}$} & & \\
\hline & & $\begin{array}{l}\text { Temp., } \\
T_{\mathrm{p}} / \mathrm{K}\end{array}$ & $\begin{array}{l}\text { Time, } \\
t_{\mathrm{p}}^{\prime} / \mathrm{min}\end{array}$ & $\begin{array}{l}\text { Temp., } \\
T_{\mathrm{h}} / \mathrm{K}\end{array}$ & $\begin{array}{l}\text { Time, } \\
t_{\mathrm{h}} / \mathrm{min}\end{array}$ & & \\
\hline Ni_Plate_1 & Plate-type ${ }^{\mathrm{a}}$ & 343 & 16 & \multicolumn{2}{|c|}{ N.P. } & Dry sorting ${ }^{\mathrm{e}}$ & For demonstrating the physical concentration process shown in \\
\hline Ni_Plate_2 & & & & \multicolumn{2}{|c|}{ N.P. } & & Fig. 1 \\
\hline Ni_Plate_3 & & & & \multicolumn{2}{|c|}{ N.P. } & & \\
\hline Ni_Plate_4 & & & & 913 & 180 & & \\
\hline Ni_Plate_5 & & & & 1173 & 180 & & \\
\hline Ni_HC_1 & Honeycomb-type ${ }^{b}$ & 353 & 15 & \multicolumn{2}{|c|}{ N.P. } & Wet sorting ${ }^{\mathrm{f}}$ & For demonstrating the physical concentration process shown in \\
\hline Ni_HC_2 & & & & 913 & 180 & & Fig. 1 \\
\hline Ni_HC_3 & & & & 1073 & 180 & & \\
\hline Ni_HC_4 & & & & 1073 & 180 & & \\
\hline Ni_Plate_SEM & Plate-type ${ }^{\mathrm{a}}$ & 343 & 16 & $\begin{array}{l}913 \text { or } \\
1173^{\mathrm{d}}\end{array}$ & 180 & N.P. & For analyzing the microstructures after Ni deposition \\
\hline Ni_HC_SEM & Honeycomb-type ${ }^{b}$ & 353 & 15 & $1073^{\mathrm{d}}$ & 180 & N.P. & \\
\hline
\end{tabular}

a: Masses were approximately $1.5 \mathrm{~g}$, and concentration of each PGM was 0.04-0.06 mass\% (see Table 4).

b: Masses were approximately $4.5 \mathrm{~g}$, and Pt, Pd, and Rh concentrations were $0.04-0.06$ mass $\%, 0.5-0.7$ mass $\%, 0.07-0.1 \mathrm{mass} \%$, respectively (see Table 4).

c: Heat treatment in vacuum after electroless plating.

$\mathrm{d}$ : A part of the samples was heated after electroless plating for SEM/EDS.

e: Sample pulverized in agate mortar was magnetically separated using Nd magnet $(\phi 30 \times 15 \mathrm{~mm})$ in air without being dispersed in liquid solvent.

$\mathrm{f}$ : Sample pulverized in agate mortar was magnetically separated using Nd magnet $(\phi 30 \times 15 \mathrm{~mm})$ after being dispersed in ethanol.

N.P.: Not performed.

Table 2 Composition of electroless Ni plating bath used in this study. The $\mathrm{pH}$ was adjusted to be $7.7 \pm 0.4$ at room temperature using $\mathrm{NaOH}$ (aq.).

\begin{tabular}{|c|c|c|}
\hline & $\begin{array}{l}\text { Composition, } \\
c_{i} / \mathrm{g} \cdot \mathrm{L}^{-1}\end{array}$ & Note $^{\mathrm{c}}$ \\
\hline $\mathrm{NiSO}_{4} \cdot 6 \mathrm{H}_{2} \mathrm{O}$ & 35.6 & $\begin{array}{l}\text { 99.0-102.0 mass\%. } \\
\text { Wako Pure Chemical Industries, Ltd. }\end{array}$ \\
\hline $\mathrm{NaHPO}_{2} \cdot \mathrm{H}_{2} \mathrm{O}^{\mathrm{a}}$ & 24.1 & $\begin{array}{l}\text { 98.8-104.2 mass\%. } \\
\text { Kanto Chemical Co., Inc. }\end{array}$ \\
\hline Glycine $^{b}$ & 22.0 & $\begin{array}{l}>95.0 \text { mass } \% . \\
\text { Kanto Chemical Co., Inc. }\end{array}$ \\
\hline $\mathrm{PbCl}_{2}$ & 0.004 & $\begin{array}{l}99.9 \text { mass } \% \text {. } \\
\text { Wako Pure Chemical Industries, Ltd. }\end{array}$ \\
\hline
\end{tabular}

a: Reducing agent.

b: Complexing agent. Chemical formula is $\mathrm{C}_{2} \mathrm{H}_{5} \mathrm{NO}_{2}$.

c: Purity and supplier of reagent.

the catalyst sample, magnetic powder, and nonmagnetic powder, respectively. Furthermore, the Ni concentration in the magnetic powder $\left(C_{\mathrm{mag}, \mathrm{Ni}}(\operatorname{mass} \%)\right)$ was calculated based on the assumption that all of the Ni deposited (Ni-4mass\% P) was distributed in the magnetic powder as follows:

$$
C_{\text {mag, Ni }}=100 \times 0.96 \times\left(w_{\text {depo }}-w_{\text {cat }}\right) / w_{\text {mag }}
$$

where $w_{\text {depo }}$ is the mass of the catalyst sample after Ni deposition.

\section{Results and Discussion}

After the electroless plating process, the catalyst samples were attached by a magnet, as shown in Fig. 6. This confirmed that ferromagnetic Ni had been successfully deposited in the absence of sensitization and activation pretreatments,

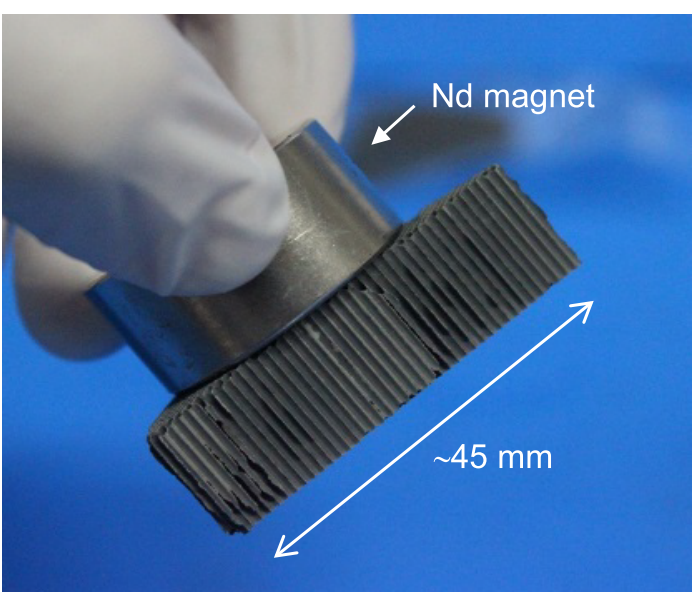

Fig. 6 Photograph of a honeycomb-type catalyst sample after electroless $\mathrm{Ni}$ plating (Exp. no. Ni_HC_5). The catalyst samples became attached to the magnet because the ferromagnetic Ni was successfully deposited on the surface of the catalyst layer.

because the PGM particles present in the catalyst layer acted as catalysts for the electroless plating process. Figure 7 shows the surface microstructures of the plate-type samples before and after $\mathrm{Ni}$ deposition (Exp. no. Ni_Plate_SEM; see Table 1). It can be seen that, after the electroless plating process, the surface of the catalyst layer of the plate-type samples was coated with Ni particles with a size of approximately $0.8 \mu \mathrm{m}$ (Fig. 7(b)). Further, it was observed that the deposited Ni particles underwent aggregation and coarsening after the heat treatment in vacuum (Fig. 7(b) and (c)). Figure 8 shows the change in the surface microstructure of the honeycomb-type samples (Exp. no. Ni_Plate_SEM; see Table 1). It can be seen 

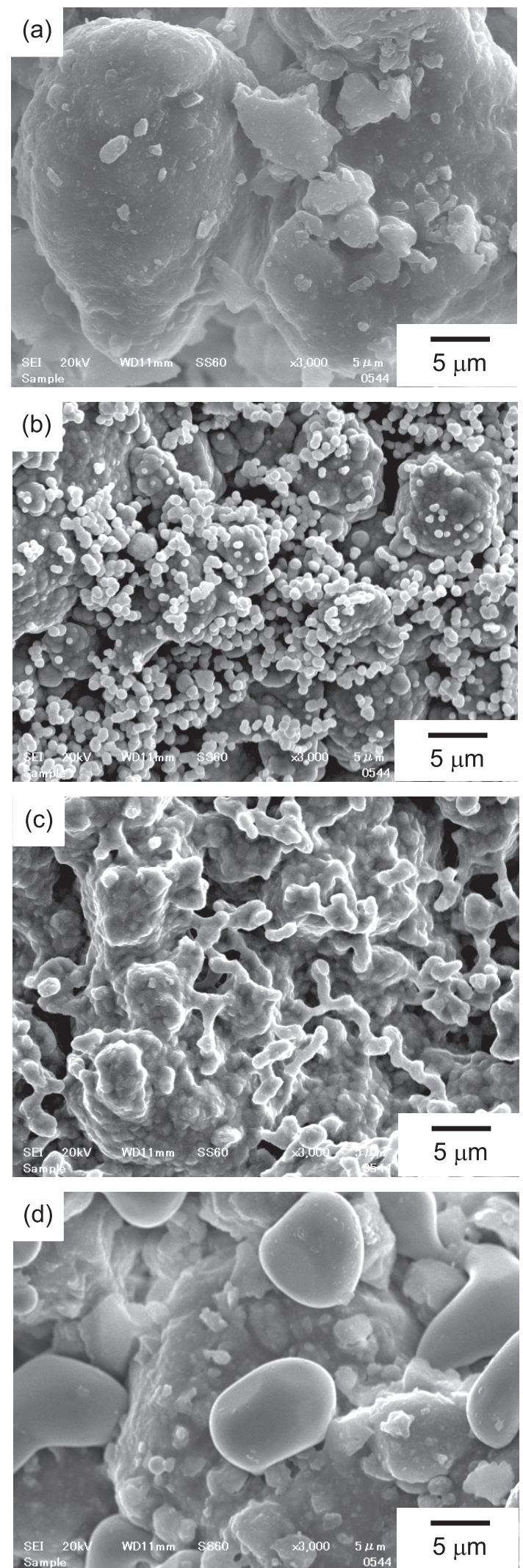

Fig. 7 SEM images of the surface of the catalyst layer of a plate-type sample: (a) before and (b) after electroless Ni plating at $343 \mathrm{~K}$ for $16 \mathrm{~min}$ (Exp. no. Ni_plate_SEM). After the electroless plating process, a heat treatment was performed (c) at $913 \mathrm{~K}$ and (d) at $1173 \mathrm{~K}$ for $3 \mathrm{~h}$ in vacuum.
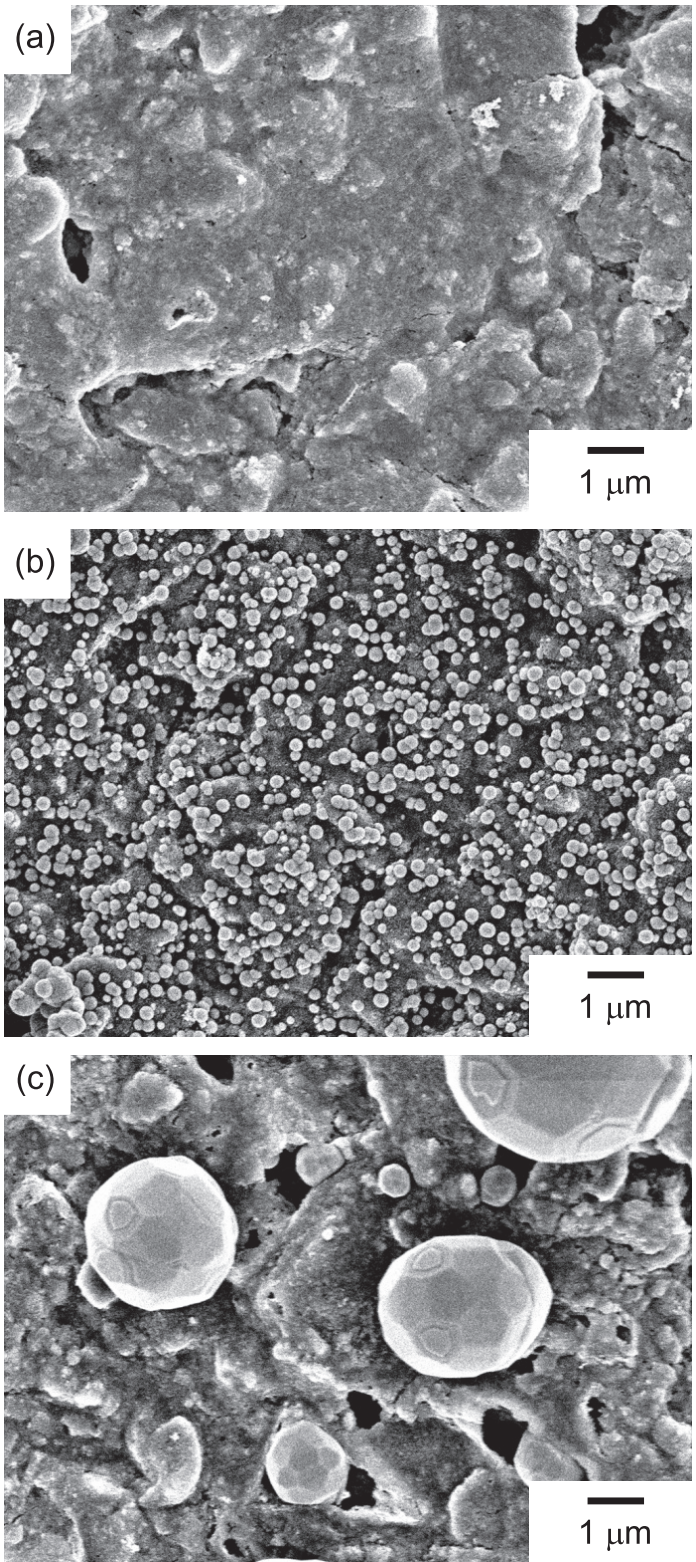

Fig. 8 SEM images of the surface of the catalyst layer of a honeycomb-type sample: (a) before and (b) after electroless Ni plating at $353 \mathrm{~K}$ for $15 \mathrm{~min}$ (Exp. no. Ni_HC_SEM). (c) After the electroless plating process, the catalyst sample was heated at $1073 \mathrm{~K}$ for $3 \mathrm{~h}$ in vacuum.

that Ni particles with a size of approximately $0.2 \mu \mathrm{m}$ were deposited on the catalyst layer after electroless plating at $353 \mathrm{~K}$ for $15 \mathrm{~min}$ (Fig. 8(b)), and that these particles coarsened after the heat treatment at $1073 \mathrm{~K}$ (Fig. 8(c)). Figure 9 and Table 3 show SEM images and the EDS results, respectively, of the cross-section of the honeycomb-type sample before and after the electroless plating process. It can be seen clearly that $\mathrm{Ni}$ was deposited even within the catalyst layer because the plating solution had penetrated its porous structure.

As shown in Fig. 10, the Ni-deposited samples could be successfully separated into magnetic and nonmagnetic powders through pulverization and subsequent magnetic separation. Table 4 lists the mass balances and PGM concentrations of the catalyst samples. For all the experiments, the Pt, Pd, and $\mathrm{Rh}$ concentrations in the magnetic powders were higher 

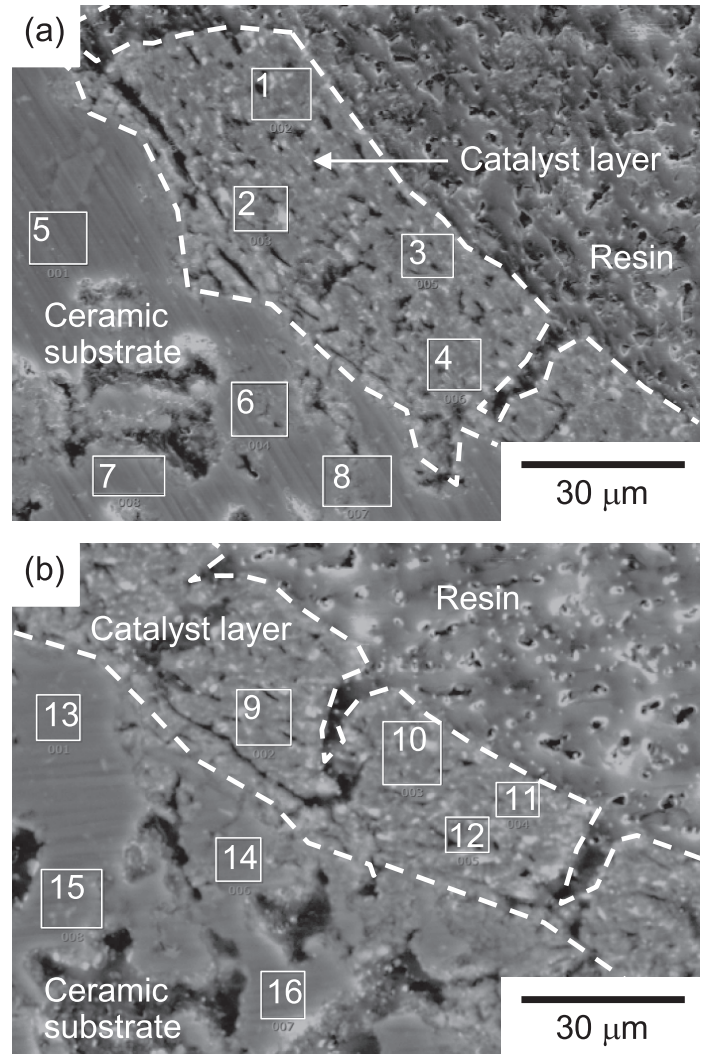

Fig. 9 Cross-sectional SEM images of a honeycomb-type sample (a) before and (b) after electroless Ni plating at $353 \mathrm{~K}$ for 15 min (Exp. no. Ni_HC_ SEM). For the microstructural observations, the samples were embedded in resin and polished. EDS results for the numbered areas are shown in Table 3.
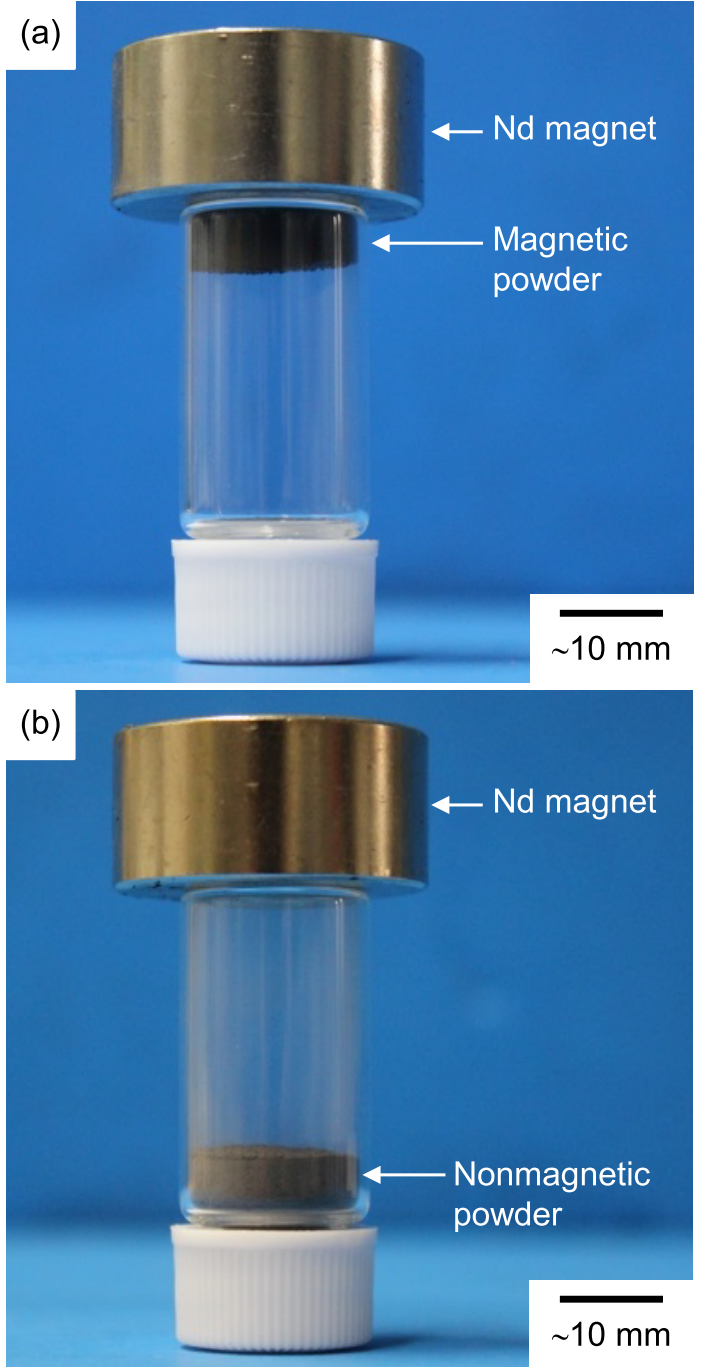

Fig. 10 Photographs of the (a) magnetic and (b) nonmagnetic powders recovered by magnetic separation (Exp. no. Ni_HC_5).

Table 3 Results of EDS of the cross-section of honeycomb-type sample before and after electroless Ni plating (Exp. no. Ni_HC_SEM). The analyzed positions are shown in Fig. 9.

\begin{tabular}{|c|c|c|c|c|c|c|c|c|c|}
\hline \multirow[b]{2}{*}{ Catalyst sample } & \multirow[b]{2}{*}{ Position $^{\mathrm{a}}$} & \multicolumn{7}{|c|}{ Concentration of element $i, C_{i}(\operatorname{mass} \%)^{\mathrm{b}}$} & \multirow[b]{2}{*}{ Note } \\
\hline & & $\mathrm{Ni}$ & $\mathrm{Mg}$ & $\mathrm{Al}$ & $\mathrm{Si}$ & $\mathrm{Fe}$ & $\mathrm{Zr}$ & $\mathrm{Ce}$ & \\
\hline Honeycomb-type & 1 & N.D. & N.D. & 51.5 & 1.4 & N.D. & 32.6 & 14.4 & Catalyst layer \\
\hline \multirow[t]{6}{*}{ before electroless plating } & 3 & N.D. & N.D. & 51.8 & 1.0 & 0.3 & 32.8 & 14.0 & \\
\hline & 4 & N.D. & N.D. & 53.3 & 1.2 & 0.2 & 31.4 & 13.9 & \\
\hline & 5 & N.D. & 10.6 & 32.0 & 55.3 & 2.1 & N.D. & N.D. & Ceramic substrate \\
\hline & 6 & 0.2 & 9.7 & 31.6 & 49.5 & 1.9 & 4.9 & 2.3 & \\
\hline & 7 & N.D. & 10.5 & 31.1 & 56.6 & 1.8 & N.D. & N.D. & \\
\hline & 8 & N.D. & 7.8 & 32.3 & 38.3 & 1.2 & 15.0 & 5.3 & \\
\hline \multirow{7}{*}{$\begin{array}{l}\text { Honeycomb-type } \\
\text { catalyst sample } \\
\text { after electroless plating }\end{array}$} & 9 & 2.2 & N.D. & 73.7 & 1.0 & 0.1 & 18.6 & 4.5 & Catalyst layer \\
\hline & 10 & 2.6 & N.D. & 73.5 & 0.9 & N.D. & 18.7 & 4.2 & \\
\hline & 11 & 3.3 & N.D. & 74.8 & 1.0 & 0.1 & 16.9 & 3.9 & \\
\hline & 13 & N.D. & 11.8 & 31.2 & 56.0 & 0.9 & N.D. & N.D. & Ceramic substrate \\
\hline & 14 & N.D. & 11.6 & 32.3 & 54.7 & 0.8 & 0.3 & 0.2 & \\
\hline & 15 & N.D. & 11.5 & 30.8 & 55.7 & 1.9 & N.D. & N.D. & \\
\hline & 16 & N.D. & 11.7 & 31.8 & 55.4 & 1.0 & N.D. & 0.1 & \\
\hline
\end{tabular}

a: See Fig. 9.

b: Analyzed by EDS; oxygen and other gaseous elements were excluded.

N.D.: Practically not detected $(<0.1$ mass $\%)$. 
than those in the corresponding catalyst sample before processing. When the plate-type samples were processed, the resulting nonmagnetic powders contained the PGMs in negligible amounts. On the other hand, the nonmagnetic powders derived from the honey-comb-type samples contained the PGMs in relatively high concentrations. Table 4 also shows the $\mathrm{Ni}$ concentrations in the magnetic powders. The Ni concentration in the magnetic powders was estimated to be 1831 mass $\%$ in the case of the plate-type samples and 1018 mass \% in the case of the honeycomb-type samples.

In order to quantitatively evaluate the process efficiency, the enrichment factor $\left(F_{i}\right)$ and recovery rate $\left(R_{i}(\%)\right)$ of the PGMs were calculated as follows:

$$
\begin{gathered}
F_{i}=C_{i, \mathrm{mag}} / C_{i, \mathrm{cat}} \\
R_{i}=100 \times\left(C_{i, \mathrm{mag}} \times w_{\mathrm{mag}}\right) /\left(\left(C_{i, \mathrm{mag}} \times w_{\mathrm{mag}}\right)+\left(C_{i, \mathrm{nmag}} \times w_{\mathrm{nmag}}\right)\right)
\end{gathered}
$$

The obtained results are shown in Table 5. In the case of the plate-type samples, physical concentration without the postplating heat treatment increased the concentrations of $\mathrm{Pt}, \mathrm{Pd}$, and Rh by 3.5-6.8 times, and 95\% or more of the PGMs were recovered in the form of the magnetic powder. Table 5 also shows that performing the heat treatment after the electroless plating process did not increase the PGM enrichment factor significantly. In this study, pulverization and magnetic sepa-

\begin{tabular}{|c|c|c|c|c|c|c|c|c|c|c|c|c|c|c|c|}
\hline \multirow[b]{3}{*}{ Exp. no. } & \multicolumn{5}{|l|}{ Catalyst sample } & \multirow{3}{*}{$\begin{array}{l}\text { Mass of } \\
\text { Ni-deposited } \\
\text { sample, } \\
w_{\text {depo }} / g\end{array}$} & \multicolumn{5}{|c|}{ Magnetic powder } & \multicolumn{4}{|c|}{ Non-magnetic powder } \\
\hline & \multirow[b]{2}{*}{ Type } & \multirow{2}{*}{$\begin{array}{l}\text { Mass, } \\
w_{\text {cat }} / \mathrm{g}\end{array}$} & \multicolumn{3}{|c|}{$\begin{array}{l}\text { Conc. of element } i \text {, } \\
C_{\text {cat }, i}(\text { mass } \%)^{\mathrm{d}}\end{array}$} & & \multirow{2}{*}{$\begin{array}{l}\text { Mass, } \\
w_{\mathrm{mag}} / \mathrm{g}\end{array}$} & \multicolumn{4}{|c|}{$\begin{array}{l}\text { Conc. of element } i, \\
C_{\mathrm{mag}, i}(\mathrm{mass} \%)\end{array}$} & \multirow{2}{*}{$\begin{array}{l}\text { Mass, } \\
w_{\text {nmag }} / \mathrm{g}\end{array}$} & \multicolumn{3}{|c|}{$\begin{array}{l}\text { Conc. of element } i, \\
C_{\text {nmag, } i}(\operatorname{mass} \%)\end{array}$} \\
\hline & & & $\mathrm{Pt}$ & $\mathrm{Pd}$ & $\mathrm{Rh}$ & & & $\mathrm{Pt}^{\mathrm{e}}$ & $\mathrm{Pd}^{\mathrm{e}}$ & $\mathrm{Rh}^{\mathrm{e}}$ & $\mathrm{Ni}^{\mathrm{f}}$ & & $\mathrm{Pt}^{\mathrm{e}}$ & $\mathrm{Pd}^{\mathrm{e}}$ & $\mathrm{Rh}^{\mathrm{e}}$ \\
\hline Ni_Plate_1 & Plate-type & 1.436 & 0.058 & 0.054 & 0.054 & 1.498 & 0.336 & 0.25 & 0.23 & 0.23 & 18 & 1.142 & N.D. & N.D. & N.D. \\
\hline Ni_Plate_2 & & 1.523 & 0.043 & 0.043 & 0.041 & 1.579 & 0.224 & 0.28 & 0.29 & 0.28 & 24 & 1.346 & 0.002 & N.D. & N.D. \\
\hline Ni_Plate_3 & & 1.390 & 0.054 & 0.048 & 0.051 & 1.511 & 0.374 & 0.19 & 0.17 & 0.18 & 31 & 1.113 & 0.003 & 0.003 & 0.003 \\
\hline Ni_Plate_4 ${ }^{\mathrm{a}}$ & & 1.488 & 0.054 & 0.052 & 0.050 & 1.556 & 0.282 & 0.27 & 0.26 & 0.25 & 23 & 1.255 & 0.003 & 0.003 & 0.003 \\
\hline Ni_Plate_5 ${ }^{b}$ & & 1.481 & 0.057 & 0.055 & 0.052 & 1.545 & 0.274 & 0.29 & 0.28 & 0.27 & 22 & 1.240 & 0.004 & 0.004 & 0.003 \\
\hline $\mathrm{Ni} \_\mathrm{HC} \_1$ & Honeycomb-type & 4.636 & 0.050 & 0.70 & 0.095 & 4.859 & 1.784 & 0.071 & 1.1 & 0.12 & 12 & 2.936 & 0.036 & 0.44 & 0.077 \\
\hline $\mathrm{Ni} \_\mathrm{HC} \_2^{\mathrm{a}}$ & & 4.613 & 0.040 & 0.48 & 0.070 & 4.794 & 1.399 & 0.063 & 0.79 & 0.097 & 12 & 3.373 & 0.028 & 0.33 & 0.055 \\
\hline $\mathrm{Ni} \_\mathrm{HC} \_3^{\mathrm{c}}$ & & 4.780 & 0.052 & 0.66 & 0.091 & 5.058 & 1.456 & 0.082 & 1.1 & 0.12 & 18 & 3.499 & 0.037 & 0.45 & 0.074 \\
\hline $\mathrm{Ni} \_\mathrm{HC} \_4^{\mathrm{c}}$ & & 4.526 & 0.057 & 0.58 & 0.10 & 4.657 & 1.321 & 0.093 & 0.94 & 0.14 & 10 & 3.324 & 0.041 & 0.42 & 0.083 \\
\hline
\end{tabular}

Table 4 Masses and compositions of catalyst samples before and after processing.

a: Heat treatment was performed at $913 \mathrm{~K}$ for $3 \mathrm{~h}$ after electroless plating.

b: Heat treatment was performed at $1173 \mathrm{~K}$ for $3 \mathrm{~h}$ after electroless plating.

c: Heat treatment was performed at $1073 \mathrm{~K}$ for $3 \mathrm{~h}$ after electroless plating.

$\mathrm{d}$ : Evaluated based on the mass and composition of magnetic and non-magnetic powders. $C_{\text {cat }, i}=\left(C_{\text {mag }, i} \times w_{\text {mag }}+C_{\text {nmag }, i} \times w_{\text {nmag }}\right) / w_{\text {cat }}$.

e: Determined by ICP-AES.

f: Calculated while assuming that all of the Ni deposit was distributed in the magnetic powder and that the Ni deposit contained 4 mass $\%$ P. $C_{\text {mag, Ni }}=100 \times 0.96 \times\left(w_{\text {depo }}-w_{\text {cat }}\right) / w_{\text {mag }}$.

N.D.: Practically not detected $(<0.001$ mass $\%)$.

\begin{tabular}{|c|c|c|c|c|c|c|c|}
\hline \multirow[b]{2}{*}{ Exp. no. } & \multirow[b]{2}{*}{ Type of catalyst sample } & \multicolumn{3}{|c|}{ Enrichment factor of element $i, F_{i}^{\mathrm{d}}$} & \multicolumn{3}{|c|}{ Recovery rate of element $i, R_{i}(\%)^{\mathrm{e}}$} \\
\hline & & $\mathrm{Pt}$ & $\mathrm{Pd}$ & $\mathrm{Rh}$ & $\mathrm{Pt}$ & $\mathrm{Pd}$ & $\mathrm{Rh}$ \\
\hline Ni_Plate_1 & Plate-type & 4.3 & 4.3 & 4.3 & $100^{\mathrm{f}}$ & $100^{f}$ & $100^{\mathrm{f}}$ \\
\hline Ni_Plate_3 & & 3.5 & 3.5 & 3.5 & 96 & 95 & 95 \\
\hline Ni_Plate_4 ${ }^{\mathrm{a}}$ & & 5.0 & 5.0 & 5.0 & 95 & 95 & 95 \\
\hline Ni_Plate_5 & & 5.1 & 5.1 & 5.1 & 94 & 94 & 95 \\
\hline Ni_HC_1 & Honeycomb-type & 1.4 & 1.6 & 1.3 & 55 & 60 & 49 \\
\hline $\mathrm{Ni} \_\mathrm{HC} \_2^{\mathrm{a}}$ & & 1.6 & 1.6 & 1.4 & 48 & 50 & 42 \\
\hline $\mathrm{Ni} \_\mathrm{HC} 3^{\mathrm{c}}$ & & 1.6 & 1.7 & 1.3 & 48 & 50 & 40 \\
\hline $\mathrm{Ni} \_\mathrm{HC} 4^{\mathrm{c}}$ & & 1.6 & 1.6 & 1.4 & 47 & 47 & 40 \\
\hline Ni_HC_5 ${ }^{\mathrm{c}}$ & & 1.4 & 1.5 & 1.2 & 56 & 59 & 49 \\
\hline
\end{tabular}

Table 5 Enrichment factor and recovery rate values of PGMs.

a: Heat treatment was performed at $913 \mathrm{~K}$ for $3 \mathrm{~h}$ after electroless plating.

b: Heat treatment was performed at $1173 \mathrm{~K}$ for $3 \mathrm{~h}$ after electroless plating.

c: Heat treatment was performed at $1073 \mathrm{~K}$ for $3 \mathrm{~h}$ after electroless plating.

d: Enrichment factor of PGM; $F_{i}=C_{i, \mathrm{mag}} / C_{i, \text { cat }}$.

e: Recovery rate of PGM; $R_{i}=100 \times\left(C_{i, \mathrm{mag}} \times w_{\mathrm{mag}}\right) /\left(\left(C_{i, \mathrm{mag}} \times w_{\mathrm{mag}}\right)+\left(C_{i, \mathrm{nmag}} \times w_{\mathrm{nmag}}\right)\right)$.

f: $C_{i, \text { nmag }}$ was less than the detection limit of ICP-AES $(<0.001$ mass $\%)$. 
ration were performed using primitive means. The enrichment factors of the PGMs will increase further if the process parameters are optimized. When the honeycomb-type samples were processed, the enrichment factors and recovery rates of the PGMs were lower than expected. Regardless of whether the post-plating heat treatments were performed or not, the enrichment factors were smaller than 2 and the recovery rates were lower than $60 \%$. Furthermore, for each case, the enrichment factor and recovery rate of $\mathrm{Rh}$ were lower than those of $\mathrm{Pt}$ and $\mathrm{Pd}$. The reasons for this phenomenon are unclear at this stage and are being investigated. However, it is believed that the amount of Ni deposited was too small to allow for the effective recovery of the PGMs by a hand magnet and that the Rh particles on the honeycomb-type samples exhibited a lower catalytic activity with respect to the electroless deposition reaction than did the Pt and Pd particles. In any case, the optimization of the plating, pulverization, and magnetic separation conditions is essential for further improving the PGM separation and concentration efficiencies.

The results of this study confirmed that the process for the physical concentration of PGMs shown in Fig. 1 is a feasible one. However, the efficiency of the process is low for it to be of current practical use. Further, the samples used in this study were not actual spent automobile catalysts. The optimization of the process conditions as well as experiments performed on actual spent catalyst samples will be needed to further establish the feasibility of the proposed physical concentration process. It should also be noted that, in principle, the proposed process does not require a large-scale plant and can be completed in a relatively short time. Thus, this process should make it possible to concentrate PGMs at the scrapping sites for old automobiles.

\section{Summary}

A new technique for physically concentrating $\mathrm{Pt}, \mathrm{Pd}$, and $\mathrm{Rh}$ from spent automobile catalysts in a more efficient and environmentally friendly manner was studied. The PGMs to be recovered exist only in the porous catalyst layer, and the primary components of such catalysts are usually ceramics such as cordierite and alumina. The proposed physical concentration process involves the electroless deposition of $\mathrm{Ni}$ on the PGM particles and the PGM-containing catalyst layer, so that the PGMs can be recovered and concentrated through magnetic separation. Experiments were performed using samples that simulated automobile catalysts. By using a plating bath containing sodium hypophosphate and glycine as the reducing and complexing agents, respectively, ferromagnetic $\mathrm{Ni}$ was successfully plated on the porous catalyst layer without requiring complicated pretreatments such as sensitization and activation. Furthermore, the results of the magnetic separation process performed after $\mathrm{Ni}$ deposition and subsequent pulverization proved that the PGMs could indeed be extracted and concentrated in the form of a magnetic powder. The PGM separation and concentration efficiencies achieved in this study were not high enough for the proposed method to be suitable for practical use, and the process needs to be optimized. However, the results of this study showed clearly that the proposed physical concentration process is a feasible one and should be useful as a pretreatment for the currently used metallurgical recycling processes.

\section{Acknowledgements}

The authors thank Mr. Katsuo Suga (Nissan Motor Co., Ltd.) for the providing the automobile catalysts used in this study. The authors are also grateful to Mr. Taketo Torii (Nippon PGM Co., Ltd.), Mr. Yuzuru Nakamura (Dowa Metals \& Mining Co., Ltd.), Dr. Akihiko Okuda, Mr. Takuo Shibazaki, Mr. Atsuhiko Yanagisawa (Tanaka Kikinzoku Kogyo K. K.), Ms. Tomoko Yanagisawa (Tanaka Holdings Co., Ltd.), Mr. Hisao Kimura, Prof. Kazuki Morita, Dr. Akihiro Yoshimura, Mr. Ryohei Yagi (The University of Tokyo), and Dr. Kasuhiro Nose (The University of Tokyo, currently with JX Nippon Mining \& Metals Corporation) for their valuable suggestions and comments. Furthermore, the authors thank Mr. Akinari Suzue (The University of Tokyo, currently with Sumitomo Metal Mining Co., Ltd.) for providing assistance during the preliminary study. This research was financially supported by the Japan Society for the Promotion of Science (JSPS) through a Grant-in-Aid for Scientific Research (S) (KAKENHI Grant No. 26220910).

\section{REFERENCES}

1) Johnson Matthey: PGM Marker Report May 2016 Summary of Platinum Supply \& Demand in 2015 (Johnson Matthey Plc., 2016) http:// www.platinum.matthey.com/services/market-research/pgm-marketreports.

2) F. K. Crundwell, M. S. Moats, V. Ramachandran, T. G. Robinson, and W. G. Davenport: Extractive Metallurgy of Nickel, Cobalt and Platinum-Group Metals (Elsevier, Oxford, UK, 2011).

3) R. K. Mishra: Proceedings of the 17th International Precious Metals Conference (International Precious Metals Institute, 1993) pp. 449474.

4) F. Habashi (ed.): Handbook of Extractive Metallurgy (VCH Verlagsgesellschaft mbH, Weinheim, Germany, 1997) vol. III, pp. 1269-1326.

5) A.J. Naldrett, D.G. Innes, J. Sowa and M.P. Gorton: Econ. Geol. 77 (1982) 1519-1534.

6) R. T. Jones: Proceedings of the International Symposium on Nickel and Cobalt (Canadian Institute of Mining, Metallurgy and Petroleum, 2005) $147-178$.

7) J.E. Hoffmann: JOM 40 (1988) 40-44.

8) J. Shibata and A. Okuda: Shigen-to-Sozai 118 (2002) 1-8

9) F.L. Bernardis, R.A. Grant and D.C. Sherrington: React. Funct. Polym. 65 (2005) 205-217.

10) M.K. Jha, J. Lee, M. Kim, J. Jeong, B. Kim and V. Kumar: Hydrometallurgy 133 (2013) 23-32.

11) S. Suzuki, M. Ogino and T. Matsumoto: Journal of MMIJ 123 (2007) 734-736 (in Japanese).

12) R. F. Burnham, J. E. Harry, A. Gibbon: European Patent, No. 0096493 A2 (1983)

13) M. Benson, C.R. Bennett, J.E. Harry, M.K. Patel and M. Cross: Resour. Conserv. Recycling 31 (2000) 1-7.

14) S. Owada, H. Seshimo, M. Miyashita, and K. Fujiwara: Proceedings of the 2nd International Symposium on East Asian Resources Recycling Technology (1993) 69-77.

15) S. Owada, Y. Tsubuku, and H. Nakayama: Proc. MMIJ Spring Meeting (The Mining and Materials Processing Institute of Japan, 1994) 282283 (in Japanese).

16) S. Owada, Y. Tsubuku, and T. Ayase: Proc. MMIJ Spring Meeting (The Mining and Materials Processing Institute of Japan, 1995) 107 (in Japanese)

17) S. Owada and K. Shinoda: Proc. MMIJ Spring Meeting (The Mining and Materials Processing Institute of Japan, 2006) 69-70 (in Japanese).

18) W. Kim, B. Kim, D. Choi, T. Oki and S. Kim: J. Hazard. Mater. 183 (2010) 29-34. 
19) T. Ichinose, G. Liu, A. Tokumaru, S. Owada: Proc. MMIJ Spring Meeting (The Mining and Materials Processing Institute of Japan, 2012) 204-205 (in Japanese).

20) G. Liu, T. Ichinose, A. Tokumaru and S. Owada: Mater. Trans. 55 (2014) 978-985.

21) G. Liu, T. Ichinose, S. Owada: Proc. MMIJ Spring Meeting (The Mining and Materials Processing Institute of Japan, 2012) 206-207.

22) G. Liu, A. Tokumura and S. Owada: Resources Processing 60 (2013) 28-35.

23) T. H. Okabe and J Mitsui: Japan Patent, No. JP2013-147702A (2013), No. JP5946034 (2016).

24) T. H. Okabe, K. Nose, and Y. Taninouchi: Proc. MMIJ Spring Meeting (The Mining and Materials Processing Institute of Japan, 2014) No. 22-2 (in Japanese).
25) Y. Taninouchi, A. Suzue, and T. H. Okabe: Proc. 53rd Annual Conference of Metallurgists (COM 2014) (Canadian Institute of Mining, Metallurgy and Petroleum, 2014).

26) Y. Taninouchi, A. Suzue, T. Watanabe, and T. H. Okabe: Proc. MMIJ Spring Meeting (The Mining and Materials Processing Institute of Japan, 2015) (in Japanese).

27) S. Yamamoto and M. Takaya: U.S. Patent, No. US 2002/0197192 A1 (2002).

28) S. Yamamoto and M. Takaya: Japan Patent, No. JP2003-53152A (2003).

29) M. Etoh and H. Tokumori: Bunseki Kagaku 35 (1986) T39-T42 (in Japanese).

30) H. Sasaki and M. Maeda: Hydrometallurgy 147-148 (2014) 59-67. 